\title{
Sustainable Design Process Based on 3D Printing Technology
}

\author{
Kyunga Kim', Dong Sug Lee ${ }^{2^{*}}$ and Yung Choon Kim² \\ 'Department of Product Design, Hanyang Erica University,15588, Korea; 770k@naver.com, \\ ${ }^{2}$ Department of Product Design, Kongju National University, 1223-24, Korea; \\ lee914@kongju.ac.kr, yckim59@kongju.ac.kr
}

\begin{abstract}
Objectives: This study researches Sustainable design process using the 3D Printing fabrication. Sustainable design approach is to negotiate a problem of environment and social. 3D Printing technology attractive to fabrication fields of the new sustainable producing system. Methods/Statistical Analysis: Concerning about AM design process, this study grasped the pros and cons of design development process generally used in the design company's design development process to develop products by studding the advance research, and found out the merits of prevented process that can be applied upon AM design development. This study applied to design development process through analysis AM technology characteristics. For the suggested design process verification, its reliability was verified through face to face interview with experts and also AM technology recognition and the usefulness of the process were surveyed and were In-depth interview to designers that own company. Findings: Sustainable design process using 3D printing should be to be supported by technical development on environmentally friendly. Also it needs to support to infrastructure on 3D printing technology. Generally, it needs an underlying infrastructure that material supplies, polishing and processing technology and surface treatment. But sustainable design process using 3D printing requires support for eco-friendly materials and R\&D system. Also it needs to use environmental material and recycling material. Secondary it should be obliged to control the air pollution technology. This air pollution Control System needs to provide everything necessary to maintain complete comfort in a manufacturing environment, including heating, cooling, humidity control, and air filtration and circulation. Consequently, this tech requires related Politics and Laws. Such as Politics and Laws is in regard to environmental problem, responsibility for using environmental material, restrictions of bad gas exhaust. However, the most important thing is to get the public value. This value formation, crucial decisions can be made early in the design process, saving the energy and resource of design. Therefore, it should have a very close-knit involvement in advanced environmental management techniques and policies as taking designer's responsibility. Improvements/Applications: the next step, this study needs to environmentalfriendly technical support reducing environmental problem, environmental regulation and technical supported policy and establishes the system, closely enrolled network system with manufacturer, Technology and government. Therefore, integrated network system, able to connect each element is requested.
\end{abstract}

Keywords: 3D Printing, Design Process. Product Fabrication; Production; Sustainable Design

\section{Introduction}

In modern times, fabrication system brings out overconsumption and over-producing. It is to cause Social Problem such as environmental Problem and industrial pollution. It Threaten the survival of the human and society at large. This Social issue demanded substantiality to design. Accordingly, Design should be conscious sustainable issue. 3D Printing is additive manufacturing system. It facilitates more rapid and any figuration. And reduce the source and waste. Also 3D printing easy to producing product with $3 \mathrm{D}$ design file. It means that it is possible to personal manufacturing. It means that it is possible to

${ }^{*}$ Author for correspondence 
reduce the producing. Thus it requires to guidelines of sustainable design for personal manufacturing.

3D Printing producing system can be easily design by using 3D scanner and 3D Program development. Also this technology uses additive method ${ }^{1}$. It is possible to produce a product at one go in any shape. It means to be possible to be in low cost without manufacture by several molding or using many kinds of equipment ${ }^{2}$. The This matters mean that the Person can various participate in all steps such as plan, design, manufacture, production, and sales as well as production industry's new arrangement, supported by progressive $3 \mathrm{~d}$ Printing technology ${ }^{3}$.

3D Printing producing system can be easily design by using 3D scanner and 3D Program development. Also this technology uses additive method. It is possible to produce a product at one go in any shape. It means to be possible to be in low cost without manufacture by several molding or using many kinds of equipment. The This matters mean that the Person can various participate in all steps such as plan, design, manufacture, production, and sales as well as production industry's new arrangement, supported by progressive $3 \mathrm{~d}$ Printing technology ${ }^{4}$. In Information-Oriented Age Speedy growth of IT industrial and development of $3 \mathrm{D}$ printer technique is to poster the digital fabrication and shifted production paradigm. According to today's quantum leap forward digital technology, everyone can be easily to access to design from sales by cooperation on the on-line network platform ${ }^{5}$. It makes consumer Centered production. It means personalized and flexible production system ${ }^{6}$. This change will give individuals empowerment in alternative of Production system, and this will clue changes throughout the manufacturing process.

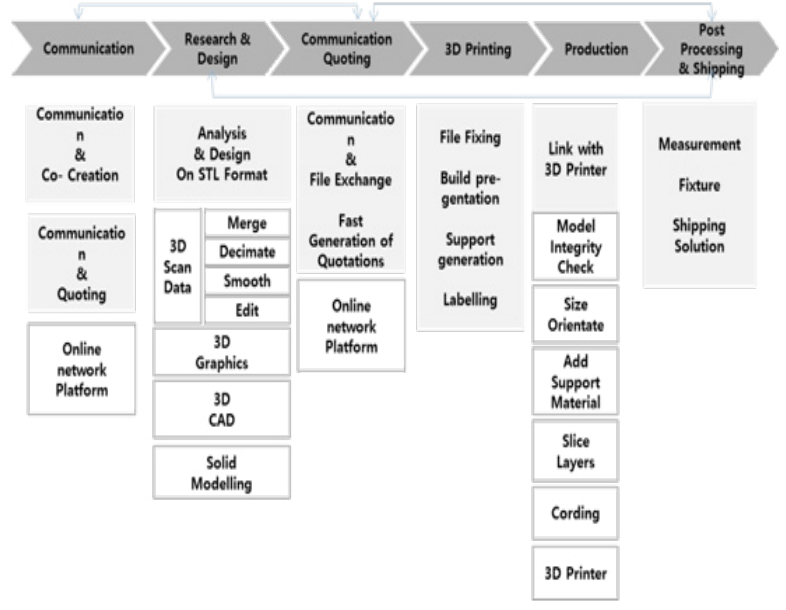

Figure 1. Producing process using $3 \mathrm{~d}$ printing

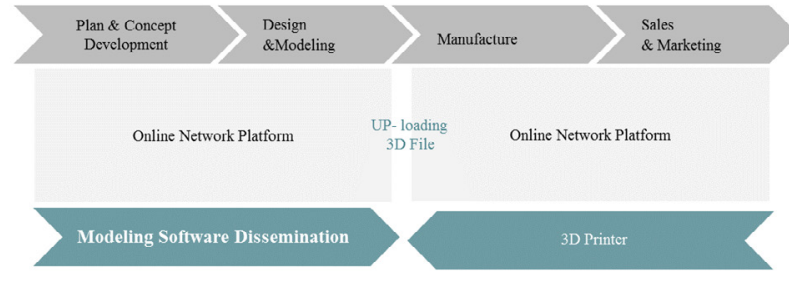

Figure 2.3D printing base on personal producing

\section{Proposed Work}

Sustainable Issue is constantly mentioned during and after a generation. Also Sustainable approach of design has been studied. Additionally, several categories of studies have kept proceeded. Such design Approach of sustainability is studied by Victor Papanek, William McDonough, EzioManzini and so on. They contained conception of social, economy, environment and social consciousness. Nowadays Sustainable designs include meaning of Eco design, Environmental design, and ecology design. It is aimed to maintain the nature and provided a new value to the environment issue. Also, focus on the influence on future generation. Namely, the conception of sustainability comprises environmental issue, social meaning, economic meaning and cultural area through the past, the present, and the future further $\frac{6-8}{\text {. }}$.

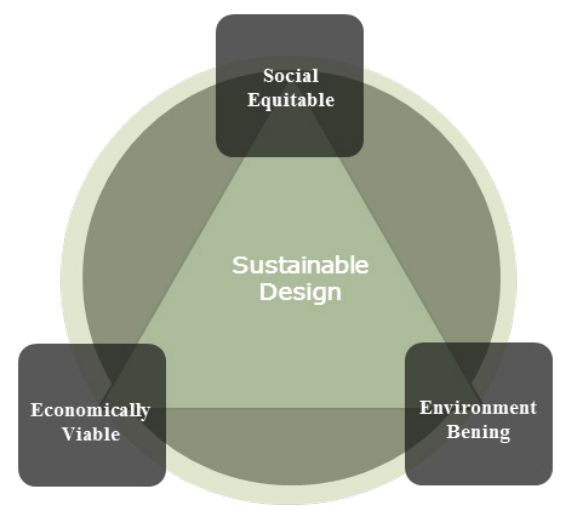

Figure 3. The aim of sustainable design by scholars

Producing system using 3D printing Producing system is to take care of several parts of sustainable Producing.

Realization of $3 \mathrm{~d}$ printing Producing resolves low cost for raw material, assembling cost and resource. Also it can reduce industrial waste. 3D Printing can produce by 3D digital file through which technology a product can be manufactured and modified. Therefore, the technology can reduce resource, cost and time. Also it is possible 
to make personalized product (based on needs) and simply parts' producing. Thus the product's lifecycle also is sustained. Product's recycling and product lifecycle can be realized by parts-producing, the problem on excessive manufacture of products based on simple and easy way can be predicted as well Consequently, it can be take care of wasted energy and contamination problem. Furthermore, Air pollution by energy consumption and distribution can be reduced. However, still, the problem of material like plastic might cause to environment problem. This event has been giving rise to the direct damage against human being. Also it may be caused by harmless gas from machine in manufacture area.

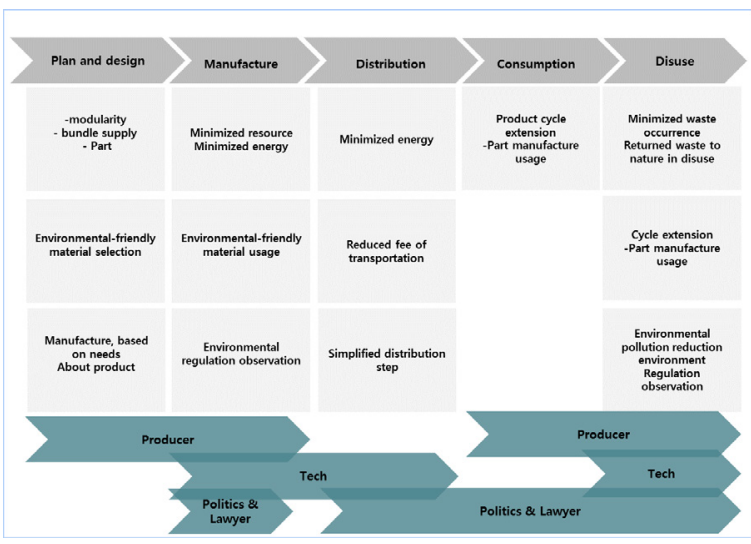

Figure 4. Sustainable design process by $3 \mathrm{~d}$ printing and roll.

In personalized manufacturing era, with the aim of approaching strategy for each sustainable design. Each person's role will be extended as the practical part of sustainability. The most important element can be mentioned as the approach to instill a personal's sense of social responsibility. Namely each personal producer has to take a sense of responsibility on the producing and maintain attitude to concern the social issue, able to be mentioned as sustainability to realize the sustainable design. The producer prevents over-production by social consciousness and environmental pollution by using environmentalfriendly materials and re-used material.

The producer has to design based on needs in Producing a product in modularized, including product's usage extension through alternative system product. It needs something that is both educational system and educational center systematically.

It should be to be supported by technical development. In order to do well on the test, you should be able to use English in everyday activities it needs to use environ- mental material and recycling material ${ }^{9}$. Also it should be obliged to control the air pollution. It requires related Politics and Laws. Such as Politics and Laws is in regard to environmental problem, obligation duty for using environmental material, restrictions of bad gas exhaust $\mathrm{t}^{\mathrm{10}}$.

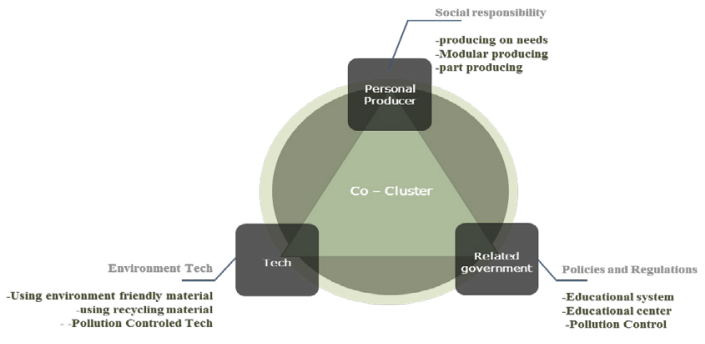

Figure 5 . Sustainable design process by $3 \mathrm{~d}$ printing and roll

\section{Conclusion}

These studies focus on sustainable design elements by producing process that can be applied to the digital era. Industrial field has a key part of several commercializing procedures; Existing Producing system is molding process, mass-production system's facilities and conveyor system. 3D Printing technology and development can reduce resource; cost and time in manufacturing the product system by simplify related process. $3 \mathrm{~d}$ printing should be alternative solution of problems in such approach aspect. Also it brings about personal producing and extension of one's role. It should need to educational support for personal producer. Also it need to requests environmental-friendly technical support, environmental regulation and technical supported policy and establishes the system, closely enrolled network system with manufacturer, Technology and government. Therefore, integrated network system, able to connect each element is requested.

\section{References}

1. Hyun CJ, Wook KS. Linking Manufacturing Strategy to Performance, 1995, p.1-30.

2. Bong C. A Study on the Technology of Rapid Prototyping in Product Design Development Process. Hongik University, 2001.

3. Cho JH, Heo S. Application of 3D Printing from the Perspective of the Consumer, Pd Issue Report, 2013 Dec, p. 14-26. 
4. Chul KJ. Counter Step of 3D Printing Industry and Construction Company, Deloitte and Touche, 2014.

5. Lee BK. The 3rd Industrial Revolution by ICT and $3 \mathrm{D}$ Printing, INDEGO Issue Crunch Report, 2012, p. 1-16.

6. Manzini E. Design for Sustainability. Design Ethnic Sustainability, 2006.

7. Papanek V. Design for the Real World: Human Ecology and Social Change, 2nd Edition, Chicaco Publisher.1985, p.368.

8. Donough WM. Cradle to Cradle, Remaking the way we Make Things. 1st Edition. North Point Press, 2002.
9. Kwak KH. Global 3D Printer Industry Technology Trend Analysis, Korea Institute and Materials Technology Policy Mechanical Engineering. 2013; 71:1-3.

10. Eun ILS, Keun SH, Uk KS. Quality Policy: Quality Management in a Manufacturing Environment using a 3D Printer, The Korea Society for Quality Management. 2014; 42(2):145-52. 